\title{
Research on the Feasibility of setting up Gas Volleyball Course in Colleges and Universities
}

\author{
Bing Liu
}

\author{
Pingxiang University, Jiangxi 337055, China \\ 57158895@qq.com
}

Key words: Gas Volleyball; colleges and universities; set up

\begin{abstract}
In recent years, the Gas Volleyball like a raging fire, has been developed and popularized vigorously, this paper studies the feasibility of Gas Volleyball setting of Public Physical Education in universities, colleges and universities to lay a theoretical basis for the introduction of Gas Volleyball, in order to make the Gas Volleyball get better development, and promote the popularization of Gas Volleyball in Colleges and universities to promote and.

Volleyball is popular among college students in the degree of reduced year by year, The development situation is not optimistic because of low interest, difficult to learn, easily injured, and the foundation of the masses is not high, the sports option class because enrollment is too small. It is no way to carry out the project of Gas volleyball. But because of the gas volleyball has the function of athletics, body building, entertainment and so on, make it grow fast in a short period of time. Colleges and universities should use and develop a variety of curriculum resources, under the background of the development of sunshine sports in Colleges and Universities, Gas Volleyball in Colleges and universities to carry out the inevitable has a very broad future.
\end{abstract}

\section{The advantages of open air volleyball project in Colleges and Universities}

\subsection{Characteristics of air volleyball}

Gas Volleyball weighs about 120 grams, the circumference of $74-86 \mathrm{~cm}$, the venue for the $12 \times 6$, net height (male $2.0 \mathrm{~m}$, female $1.8 \mathrm{~m}$ ), the number of entries for 5 people, compared with the ordinary volleyball, from the size of the ball, as well as the venue, higher net and hard volleyball. More than simple Gas Volleyball made of soft plastic. The color of the ball is yellow, blue, Gas Volleyball is a new weight loss, and keep the characteristics of volleyball speed. These characteristics of Gas Volleyball, reducing the service difficulty, reduces the skill of volleyball game is reduced when the ball's flight speed, batting style increase, exercise and play in the arm swelling, pain uncomfortable situation is greatly reduced, the new scholars no longer on the Gas Volleyball is full of tension and fear, volleyball spiking success rate and a substantial increase in the degree of wonderful, smashing success, smashing the wonderful team to bring inspiration to those involved in spiking happiness and a sense of success. Because of high drop, the low success rate of block increases, in the game in the offensive and defensive side in the game can experience the feeling of success and enhance confidence.

\subsection{Is not high on the sports ground}

Most of the colleges and universities are lack of sports teaching venues, sports facilities behind the old problems. The few specially set up Gas Volleyball venues, we only rational use of existing and development of sports venues and sports facilities, the badminton court, tennis court or library Hall of Gas Volleyball Teaching and Gas Volleyball Teaching and training and competition. Extracurricular sports activities and the price is not expensive, affordable, on the environment destruction facilities is not strong, the safety is high.

\subsection{Gas Volleyball Sports safety, easy to learn, the rules of the game is relatively loose}

Gas volleyball spike weight, does not make the injured students have no pressure, do not damage on the environment facilities. Gas Volleyball in terms of technology requirements low, can be used in his hands the ball, ball, pass the ball to learn very easy to use, the entry is not difficult, as long as the early scholars learn seriously, after a short period the training, will be able to participate in the gas volleyball competition. The Gas Volleyball digs, spiking skill action, relatively easy to grasp, 
flexible and relaxed, the game ball in the air increases the number of students and, to better understand the sports participation of interest.

\section{The feasibility study of the implementation of Gas Volleyball in Colleges and Universities}

\subsection{PE Teaching Reform}

At present, with the promotion of the network, the cost of mobile phone network is more and more low, coupled with the network game, strong attraction information, many students internet addiction, plus college physical education curriculum content obsolete, backward teaching methods and other reasons, most of the students of physical education is not high enthusiasm of students in physical education is to cope with, or the physical education curriculum as a free and relaxed, as long as the teacher attendance is completed, or practice, some students began classes, some students use mobile phone access to the Internet, some students in the heart is not in it. Under these circumstances, Deepen the reform of physical education must begin immediately, the introduction of new sports has become a must in Colleges and universities. The gas volleyball this new project is in line with the participation of college students, has attracted the attention of students so that more students away from the computer and mobile phone, actively involved in sports.

\subsection{It can develop students' physical quality}

The school sports is an important part of education, enhance the physical fitness of students, is the main task of school physical education. How to measure the physical condition of students? Physical quality is an important symbol to measure the physical condition, physical quality is through a variety of functional ability in the human body in motion. With the rapid development of social economy, steadily the improvement of people's living standards, the nutrition level of the students to follow. However, most of the students' physical quality in the fall, the most obvious is the speed, endurance, flexibility, agility. Sports workers should pay more attention, not only to cultivate the students' lifelong sports consciousness and sports have certain theoretical basis, watch sports the competition ability, but also for the mastery of one or more physical skills, improve physical fitness and sports skills through their own comprehensive exercise, physical education activities will lay a firm Solid foundation.

\subsection{Enrich extracurricular sports life, cultivate students' interest in sports}

Once learning volleyball class, many students are often playing arm pain or bruising, is hit by the ball body, a lot of students heard on the volleyball class, tension, and even depressed, enthusiasm on volleyball course is difficult to mobilize. Gas Volleyball is made of a light and soft plastic, to minimize, in it will hurt the practice of students in Volleyball caused by the body's arms, fingers will prevent damage, eliminating the generated student volleyball practice at the time of tension, unhappy mood. Gas Volleyball Technique learning is not difficult to make people happy, and have a very strong interest, leisure watch. Gas Volleyball Rules which shorten the game the site, reduce the network, reduce the skill, reduce the difficulty of movements, so the gas volleyball with continuous offensive advantage. Such as serving girls because of the power and the difficulty of service is unable to realize Serve, but it is easy to realize the gas volleyball serve, students can feel the action each serve. Pass, as long as the fingers slightly bent into a hemispherical shape, you can put the ball smoothly from the ball technology can be used to support, holding, pick and other methods. Speed is not quick, not easy to play the ball back and forth in the air, the number increased, each Ball winner for both inside and outside the field of suspense, and can improve the mood of the audience. Players can also use mixed competition, improve their ability of communication, play relaxed and happy, healthy and happy to participate in endless. Based on physical education happy experience with success, to change their attitude towards physical education, stimulate interest in sports participants, the enthusiasm of PE is greatly improved.

\subsection{Fitness needs of the whole people}

Today people pay more attention to the physical quality and more growth, development of the national fitness work has been very slow to adapt to the development of socialist modernization. The mass sports is not wide enough, people's sports fitness consciousness remains to be strengthened, rarely consciously for the three sports weekly, most people every day is on the 
computer to play games and the Internet. Today's college students is the hope and future of the country, in the campus, the gas volleyball can give them endless pleasure and a sense of achievement, the happy mood directly to every family and friends around. Gas Volleyball learning, everyone, age less are not affected, rich in the form of the site, many convenient, economical and practical, so that more people join them. Students in the school master of the gas volleyball technology, rules, after he entered the job. We will be the main force to promote the national fitness, play an active role in organizing and participating in this activity, and will greatly promote the improvement of the quality of the whole people's body.

\section{5 promote the development of College Students' physical and psychological quality education}

Gas Volleyball is a team sport, often join the Gas Volleyball learning and training, to enable students to understand the strength of the team and the spirit of unity and cooperation. In the game only unity, cooperation, mutual trust, mutual encouragement, in order to achieve the best results, so through the air volleyball training, students not only experience the team spirit of cooperation, but also cultivate a hard-working, dare to struggle, the game is not the tension. In the training ground, because the Gas Volleyball fun, players can play away from the troubles of life, relieve stress, relax the mood, often hear the training ground of laughter, this is conducive to the students relieve the pressure of learning, is conducive to the promotion of mental health. Gas Volleyball enriches the teaching content of physical education, is a new fashion sport, which makes the teaching content rich and colorful, improve students' Sports The enthusiasm, but also enrich the students to participate in extracurricular sports activities of campus culture, to further accelerate the pace of reform of the quality education. At the same time, participate in the volleyball movement can improve the nervous and cardiovascular function, improve participants interpersonal ability and enhance the friendship between the players, to improve team cohesion.

\section{3. summary}

With the community recognition of Gas Volleyball, at all levels regularly held gas volleyball match, will promote the development of Gas Volleyball in this emerging sports project. The provincial trade union, the Provincial Sports Bureau, the Municipal Sports Bureau should be a leader of the project, and vigorously promote the beneficial to the national fitness movement, multi Gas Volleyball Competition held a large city, hold the coach learning, set up a variety of awards. Only the higher level units to pay attention to it, school leaders and teachers to participate in the game, can realize the Gas Volleyball fun, Gas Volleyball Curriculum also can get the recognition and support of university leaders at all levels. Colleges and universities have a high level of sports teaching some teachers even professional volleyball teachers only need further education or self-study can be competent for the Gas Volleyball Teaching and training work. Gas Volleyball fun and can be connected with By nature will attract many students to join the Gas Volleyball site by cheap, tennis and badminton courts. Gas Volleyball on the height of students and the technical level is very low, actively join the gas volleyball training, not only can cultivate students' interest in sports, can learn a skill in a short time and enhance the physical quality of the students in sports, can experience the fun of sports, to lay a good foundation for lifelong physical education. Therefore, colleges and universities can be opened for Gas Volleyball Elective Course, but also for all the teachers and students as the school extracurricular sports activities.

\section{Reference}

[1] Zhi-yuan Cai.China's innovative Gas Volleyball and project prospect [J].Journal of Beijing Sport University, 2003 (6)

[2]A-hai Huang.On the new features of air volleyball in Colleges and universities and the promotion of [J].Journal of Zhangzhou Normal University, 2006 (3)

[3] Jian-qiu Wang.Discussion on the elective course of Volleyball in [J].sports world, 2014 (2)

[4] Jin-bo Chen. Study on the curriculum setting of physical education in universities and colleges in Hunan province [J]. School of physical education, 2014,4 (20) 